\title{
Comparative Evaluation of Analgesic Efficacy of NSAID and Opioid Post-Extraction
}

\author{
R Keerthana ${ }^{1}$ and Dhanraj Ganapathy ${ }^{2}$ \\ ${ }^{1}$ Saveetha Dental College and hospitals, Saveetha Institute of Medical and \\ Technical Sciences, Saveetha University, Chennai, India \\ Professor and Head, Department of Prosthodontics, Saveetha Dental College and hospitals, \\ Saveetha Institute of Medical and Technical Sciences, Saveetha University, Chennai, India
}

\section{ABSTRACT}

Extractions are associated with postoperative pain and swelling at the extraction site. Postoperative pain is usually moderate to severe in the first $12 \mathrm{~h}$ postoperatively and lasts for 3-5 days. However, with pain killers, these symptoms usually subside within $24 \mathrm{~h}$. The aim of the study was to compare and evaluate the analgesic effects of Ketorolac and tramadol post operatively. Total of 100 patients requiring surgical extraction under local anesthesia were taken in the study. The study group consisted of patients aged between 25-40 years undergoing extraction of the mandibular molars. The patients were randomly divided into two groups (Group A \& Group B) of 50 each. Group A patients were given Tramadol $50 \mathrm{mg}$ and Group B patients were given ketorolac $10 \mathrm{mg}$ postoperatively. Pain intensity was recorded after 30 minutes, 1st hr., 4th hrs, 6th hrs, 12th hrs and 24 hrs using the visual analog scale. Telephonic interviews were conducted to record the pain intensity of the patients. Pain was recorded on VAS (visual analogue scale). The data were coded and entered into IBM SPSS for statistical analysis. Descriptive and analytic approaches were used in the data analysis. Independent sample t test was used to compare the pain intensity in both the groups. On comparing the mean of the Visual Analog Scale it was found that the mean of Group B (Ketorolac) was found to be lesser than that of Group A (Tramadol) thus proving that Ketoralac had more analgesic effects compared to tramadol. Independent sample t test showed that the results were statistically significant. ( $p=0.021, p<0.05)$. Within the limits of the study, it was found that the maximum analgesic effect of Ketorol was achieved in 48 hours and the maximum analgesic effect of Tramadol was achieved in 72 hours and the results were statistically significant.

KEY WORDS: ANALGESIC EFFECT; KETOROLAC; TRAMADOL; PAIN INTENSITY; VISUAL ANALOG SCALE.

\section{INTRODUCTION}

Pain is a subjective symptom and can be influenced by various factors like age, sex, anxiety, pain threshold and surgical difficulty etc. pain experienced after extraction

\section{ARTICLE INFORMATION}

*Corresponding Author: dhanraj@saveetha.com

Received 10th June 2020 Accepted after revision 11th August 2020 Print ISSN: 0974-6455 Online ISSN: 2321-4007 CODEN: BBRCBA

Thomson Reuters ISI Web of Science Clarivate Analytics USA and Crossref Indexed Journal

\section{Clarivate}

NAAS Journal Score 2020 (4.31) SJIF: 2020 (7.728)

A Society of Science and Nature Publication,

Bhopal India 2020. All rights reserved.

Online Contents Available at: http//www.bbrc.in/

Doi: http://dx.doi.org/10.21786/bbrc/13.7/8 under local anesthesia has been shown to be of short duration and reaches its maximum intensity in early post-operative period which requires analgesics for relief. (Becker and Phero, 2005)Post-operative pain can cause distress to the patient and affect the patient's quality of life after surgery. So various research studies have been done for better pain control following extraction and different types of medications have been proposed. (Hyrkäs et al., 1993) Pain management for extraction should be treated before the development of significant intensity of pain. Longer the pain remains uncontrolled, more sensitive the patient may become to painful stimuli. Pain following extraction reaches a severe intensity 
or peak within the first 5-8 hrs after the surgery. (Revathy et al., 2018)

Many clinicians have attempted to reduce the postoperative pain by using anti-inflammatory drugs. The anti-inflammatory drugs broadly categorized into steroidal (Narcotic analgesics) and non-steroidal (NSAIDS). Narcotic analgesics, which act directly on the central nervous system opiate receptors, but can cause drug dependence, respiratory depression, constipation, nausea, vomiting and sedation. Non-steroidal antiinflammatory drugs (NSAIDs), which act by prostaglandin synthesis to achieve analgesic and antiinflammatory actions, (Colletti et al., 1998) but associated with poor gastrointestinal and renal tolerance and risk of interference with coagulation systems. (Gan, 2010) The best postoperative medication is one that provides long analgesic cover, is easily administrable, should be safe and cost economical. Ketorolac is a first-generation non-steroidal anti-inflammatory drug (NSAID) of family heterocyclic acetic acid derivatives, used for short-term management of moderate to severe pain and usually not prescribed for longer than five days. Ketorolac is a non-selective COX inhibitor. Its mode of action is by inhibiting the bodily synthesis of prostaglandins by competitive blocking of the enzyme cyclooxygenase (COX). Its onset of action is approximately 30 minutes and reaches its peak effects in 45-60 minutes having a half-life of 4-6 hours. (Lee and Seo, 2008)

Tramadol is a synthetic opioid of the benzenoid class used to treat moderate to severe pain both acute and chronic. Its effectiveness is equivalent to that of morphine and analgesics effects last for approximately $6 \mathrm{hrs}$. It acts by two different mechanisms. (Grond and Sablotzki, 2004) First, it works by binding to the $\mu$-opioid receptor. Secondly, it acts as a serotonin-norepinephrine reuptake inhibitor (SNRI). (Lee et al., 1993)

The use of tramadol has not reported very widely after extraction. However Ketorolac has been used successfully to replace opioid in mild-to-moderate postsurgical pain like surgical extraction. As postoperative pain after surgical extraction is moderate to severe, pain relief or control is often challenging to achieve. However, this condition offers an opportunity to study and evaluate the potency of analgesics in validated clinically relevant models. (Lustenberger, Grätz and Mutzbauer, 2011)

Previously our department has published extensive research on various aspects of prosthetic dentistry ('Evaluation of Corrosive Behavior of Four Nickelchromium Alloys in Artificial Saliva by Cyclic Polarization Test:An in vitro Study', 2017; Ganapathy, Kannan and Venugopalan, 2017; Jain, 2017a, 2017b; Ranganathan, Ganapathy and Jain, 2017; Ariga et al., 2018; Gupta, Ariga and Deogade, 2018; Anbu et al., 2019; Ashok and Ganapathy, 2019; Duraisamy et al., 2019; Varghese, Ramesh and Veeraiyan, 2019), this vast research experience has inspired us to research about the analgesic effect of Tramadol and Ketorolac post extraction.

\section{MATERIAL AND METHODS}

Data Collection: Total of 100 patients requiring surgical extraction under local anesthesia were taken in the study. The study protocol received institutional approval from the Ethics Committee of the university. The study group consisted of patients aged between 25-40 years undergoing extraction of the mandibular molars. Inclusion criteria were the patient undergoing extraction of the mandibular molars. Exclusion criteria includes medically compromised patients, pregnancy, steroid therapy, metabolic disorder patients, those who had taken any type of analgesic in the past $48 \mathrm{hrs,}$ patients allergic to the drugs and impaction extraction. All the patients who were included in the study were informed about the treatment procedure and possible complications were also explained to them. Informed consent was taken from them.

Sampling: The patients were randomly divided into two groups (Group A \& Group B) of 50 each. Group A patients were given Tramadol $50 \mathrm{mg}$ and Group B patients were given ketorolac $10 \mathrm{mg}$ postoperatively. Pain intensity was recorded after 30 minutes, 1st hr., 4th hrs, 6th hrs, 12th hrs and 24 hrs using the visual analog scale. Telephonic interviews were conducted to record the pain intensity of the patients. Comparison of pain intensity was also done on 1st, 2nd and 3rd postoperative days. Pain was recorded on VAS (visual analogue scale) [0-no pain, 2-mild pain, 4- tolerable, 6-distressful pain, 8-severe pain and 10-totally disabling pain].

Statistical Analysis: The data were coded and entered into IBM SPSS for statistical analysis. Descriptive and analytic approaches were used in the data analysis. Independent sample t test was used to compare the pain intensity in both the groups.

\section{RESULTS AND DISCUSSION}

A total of 100 patients were enrolled in the study to compare the analgesic efficacy of Ketorolac versus Tramadol and were equally divided into Group A (Tramadol) and Group B (Ketorol) included 34 males (68\%), 16 females (32\%) whereas Group B included 30 males (60\%), 20 females (40\%)

The mean of Visual Analog Scale in the first 30 minutes for Group A (Tramadol) was 7 and that of Group B (Ketorolac) was 6. After 12 hours, the mean of Group A (Tramadol) was 6 and that of Group B (Ketorolac) was 5. The mean at the end of 24 hours of Group A (Tramadol) was 5 and that of Group B (Ketorolac) was 6. The mean of Group A (Tramadol) and Group B (Ketorolac) was 4 after 36 hours. At the end of 48 hours and at 60 hours, the mean of Group A (Tramadol) was 3 and that of Group B (Ketorolac) was 1. End of 72 hours the means of both Group A (Tramadol) and Group B (Ketorolac) were 1. On comparing the mean of the Visual Analog Scale it was found that the mean of Group B (Ketorolac) was found to 
be lesser than that of Group A (Tramadol) thus proving that Ketoralac had more analgesic effects compared to tramadol. Independent sample t test showed that the results were statistically significant. $(p=0.021, p<0.05)$

Figure 1: Bar chart with error bar shows the mean of the Visual Analog Scale of both the analgesics, Ketorolac and Tramadol. $\mathrm{X}$ axis shows the time at which the pain intensity was calculated and $\mathrm{Y}$ axis shows the mean of the Visual Analog Scale. It was found that the maximum analgesic effect (1) of Ketorol (red) was achieved in 48 hours and the maximum analgesic effect (1) of Tramadol (blue) was achieved in $\mathbf{7 2}$ hours. Independent sample $t$ test showed that the results were statistically significant. $(\mathrm{p}=0.021, \mathrm{p}<0.05)$

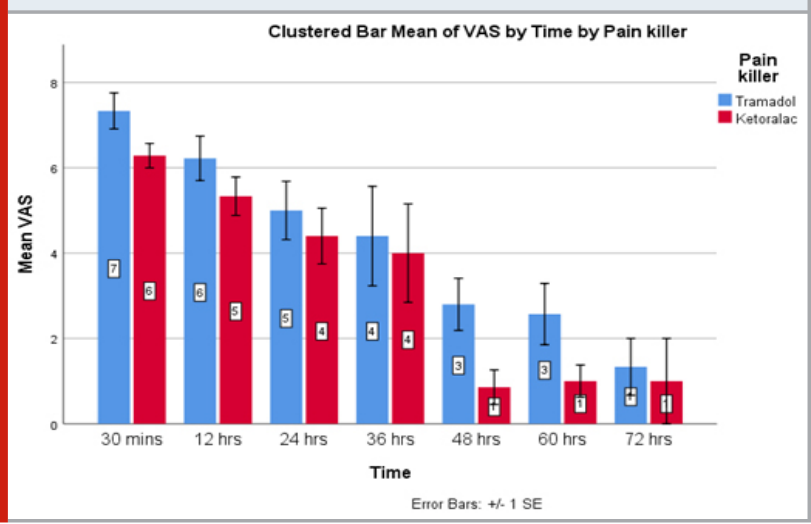

Within 24 hours, the patients using Ketorolac had a tolerable pain and the same was observed in the patients using tramadol only after 36 hours. Similar results are observed by Shaik Kim K et al. and Mario et al. Both the medications provide good analgesic effects. (Kim et al., 2009)(Isiordia-Espinoza et al., 2011) Gopal Raju et al. observed intravenous ketorolac $30 \mathrm{mg}$ provides better pain control postoperatively as compared to $50 \mathrm{mg}$ of tramadol after extraction. (Gopalraju et al., 2014) In the double-blind, randomized, clinical trial Mishra et al. 2012 proved that $100 \mathrm{mg}$ of tramadol is equally effective as $20 \mathrm{mg}$ of ketorolac in the relief of postoperative pain. (Mishra and Khan, 2012) Shah et al. 2013 in their study concluded that intramuscular $30 \mathrm{mg}$ ketorolac gives better pain management, if given prior to oral surgical procedure than intravenous $50 \mathrm{mg}$ tramadol. (Shah et al., 2013) Ong et al. 2004 showed ketorolac had better pain scores and total postoperative analgesic consumption than tramadol. (Ong et al., 2004)

Effective and safe analgesia is one of the main challenges in the healthcare industry. Tramadol is a relatively new opioid drug with better analgesic property and without the risk of tolerance and physical dependence. It is known to be a one of the safest postoperative analgesic medicine used for chronic pain management. However systematic review and meta-analysis showed that a single dose of tramadol has a lower analgesic efficacy and safety than NSAIDs in oral surgery. Ketorolac is a commonly used NSAID for the short term management of acute postoperative pain in dentistry. (Isiordia-Espinoza, de Jesús Pozos-Guillén and Aragon-Martinez, 2014) Main focus of the study was to compare the analgesic efficacy on pain intensity after tooth extraction of the commonly used analgesics, tramadol and ketorolac. The better analgesic efficacy of ketorolac in comparison to tramadol is attributed to the pathogenesis of dental pain, which is largely inflammatory and is different from general surgical pain. The evidence-based medicine has also shown that dental pain is better treated with NSAIDs than opioids.

The limitations of the study are the small sample size and the body weight which is one of the important criteria for the analgesic effect was not taken into study. Future studies can be conducted with a larger sample size and also with other criteria that influence the analgesic effect.

\section{CONCLUSION}

Within the limits of the study, it was found that the maximum analgesic effect of Ketorol was achieved in 48 hours and the maximum analgesic effect of Tramadol was achieved in 72 hours and the results were statistically significant.

Authors Contributions: First author (Keerthana R) performed the analysis, and interpretation and wrote the manuscript. Second author (Dr. Dhanraj. G) contributed to conception, data design, analysis, interpretation and critically revised the manuscript. Both the authors have discussed the results and contributed to the final manuscript.

Conflict of Interest: No conflict of interest.

\section{REFERENCES}

Anbu, R. T. et al. (2019) 'Comparison of the Efficacy of Three Different Bone Regeneration Materials: An Animal Study', European journal of dentistry, 13(1), pp. 22-28.

Ariga, P. et al. (2018) 'Determination of Correlation of Width of Maxillary Anterior Teeth using Extraoral and Intraoral Factors in Indian Population: A Systematic Review', World Journal of Dentistry, 9(1), pp. 68-75.

Ashok, V. and Ganapathy, D. (2019) 'A geometrical method to classify face forms', Journal of oral biology and craniofacial research, 9(3), pp. 232-235.

Becker, D. E. and Phero, J. C. (2005) 'Drug Therapy in Dental Practice: Nonopioid and Opioid Analgesics', Anesthesia Progress, pp. 140-149. doi: 10.2344/00033006(2005)52[140:dtd]2.0.co;2.

Colletti, V. et al. (1998) 'Intramuscular tramadol versus ketorolac in the treatment of pain following nasal surgery: a controlled multicenter trial', Current Therapeutic Research, pp. 608-618. doi: 10.1016/s0011393x(98)85059-5.

Duraisamy, R. et al. (2019) 'Compatibility of Nonoriginal Abutments With Implants: Evaluation of Microgap at 
the Implant-Abutment Interface, With Original and Nonoriginal Abutments', Implant dentistry, 28(3), pp. 289-295.

Evaluation of Corrosive Behavior of Four Nickelchromium Alloys in Artificial Saliva by Cyclic Polarization Test:An in vitro Study' (2017) World Journal of Dentistry, 8(6), pp. 477-482.

Ganapathy, D. M., Kannan, A. and Venugopalan, S. (2017) 'Effect of Coated Surfaces influencing Screw Loosening in Implants: A Systematic Review and Meta-analysis', World Journal of Dentistry, 8(6), pp. 496-502.

Gan, T. J. (2010) 'Diclofenac: an update on its mechanism of action and safety profile', Current Medical Research and Opinion, pp. 1715-1731. doi: 10.1185/03007995.2010.486301.

Gopalraju, P. et al. (2014) 'Comparative study of intravenous Tramadol versus Ketorolac for preventing postoperative pain after third molar surgery - A prospective randomized study', Journal of CranioMaxillofacial Surgery, pp. 629-633. doi: 10.1016/j. jcms.2013.09.004.

Grond, S. and Sablotzki, A. (2004) 'Clinical Pharmacology of Tramadol', Clinical Pharmacokinetics, pp. 879-923. doi: 10.2165/00003088-200443130-00004.

Gupta, P., Ariga, P. and Deogade, S. C. (2018) 'Effect of Monopoly-coating Agent on the Surface Roughness of a Tissue Conditioner Subjected to Cleansing and Disinfection: A Contact Profilometric Study', Contemporary clinical dentistry, 9(Suppl 1), pp. S122S126.

Hyrkäs, T. et al. (1993) 'A comparison of diclofenac with and without single-dose intravenous steroid to prevent postoperative pain after third molar removal', Journal of Oral and Maxillofacial Surgery, pp. 634-636. doi: 10.1016/s0278-2391(10)80261-7.

Isiordia-Espinoza, M. A. et al. (2011) 'Preemptive analgesic effectiveness of oral ketorolac plus local tramadol after impacted mandibular third molar surgery', Medicina Oral Patología Oral y Cirugia Bucal, pp. e776-e780. doi: 10.4317/medoral.16854.

Isiordia-Espinoza, M. A., de Jesús Pozos-Guillén, A. and Aragon-Martinez, O. H. (2014) 'Analgesic efficacy and safety of single-dose tramadol and non-steroidal antiinflammatory drugs in operations on the third molars: a systematic review and meta-analysis', British Journal of Oral and Maxillofacial Surgery, pp. 775-783. doi: 10.1016/j.bjoms.2014.05.005.

Jain, A. R. (2017a) 'Clinical and Functional Outcomes of Implant Prostheses in Fibula Free Flaps', World Journal of Dentistry, 8(3), pp. 171-176.

Jain, A. R. (2017b) 'Prevalence of Partial Edentulousness and Treatment needs in Rural Population of South
India', World Journal of Dentistry, 8(3), pp. 213-217. Kim, K. et al. (2009) 'The use of corticosteroids and nonsteroidal antiinflammatory medication for the management of pain and inflammation after third molar surgery: A review of the literature', Oral Surgery, Oral Medicine, Oral Pathology, Oral Radiology, and Endodontology, pp. 630-640. doi: 10.1016/j. tripleo.2008.11.005.

Lee, C. R. et al. (1993) 'Tramadol', Drugs, pp. 313-340. doi: 10.2165/00003495-199346020-00008.

Lee, I. O. and Seo, Y. (2008) 'The Effects of Intrathecal Cyclooxygenase-1, Cyclooxygenase-2, or Nonselective Inhibitors on Pain Behavior and Spinal Fos-Like Immunoreactivity', Anesthesia \&t Analgesia, pp. 972977. doi: 10.1213/ane.0b013e318163f602.

Lustenberger, F. D., Grätz, K. W. and Mutzbauer, T. S. (2011) 'Efficacy of ibuprofen versus lornoxicam after third molar surgery: a randomized, double-blind, crossover pilot study', Oral and Maxillofacial Surgery, pp. 57-62. doi: 10.1007/s 10006-010-0255-4.

Mishra, H. and Khan, F. (2012) 'A double-blind, placebo-controlled randomized comparison of pre and postoperative administration of ketorolac and tramadol for dental extraction pain', Journal of Anaesthesiology Clinical Pharmacology, p. 221. doi: 10.4103/09709185.94892.

Ong, K. S. et al. (2004) 'Preoperative ketorolac has a preemptive effect for postoperative third molar surgical pain', International Journal of Oral and Maxillofacial Surgery, pp. 771-776. doi: 10.1016/j. ijom.2004.01.020.

Ranganathan, H., Ganapathy, D. M. and Jain, A. R. (2017) 'Cervical and Incisal Marginal Discrepancy in Ceramic Laminate Veneering Materials: A SEM Analysis', Contemporary clinical dentistry, 8(2), pp. 272-278.

Revathy, N. et al. (2018) 'Comparative study on alveolar bone healing in postextraction socket versus healing aided with autologous platelet-rich fibrin following surgical removal of bilateral mandibular impacted third molar tooth: A radiographic evaluation', National Journal of Maxillofacial Surgery, p. 140. doi: 10.4103/ njms.njms_17_18.

Shah, A. V. et al. (2013) 'Comparative Evaluation of PreEmptive Analgesic Efficacy of Intramuscular Ketorolac Versus Tramadol Following Third Molar Surgery', Journal of Maxillofacial and Oral Surgery, pp. 197-202. doi: 10.1007/s12663-012-0420-4.

Varghese, S. S., Ramesh, A. and Veeraiyan, D. N. (2019) 'Blended Module-Based Teaching in Biostatistics and Research Methodology: A Retrospective Study with Postgraduate Dental Students', Journal of dental education, 83(4), pp. 445-450. 